\title{
REVIEW
}

\section{Imaging in thyroid-associated orbitopathy}

\author{
George J Kahaly \\ Department of Endocrinology/Metabolism, Gutenberg-University Hospital, Mainz, Germany \\ (Correspondence should be addressed to G J Kahaly, University Hospital, Mainz 55101, Germany; Email: kahaly@endokrinologie.klinik.uni-mainz.de)
}

\section{Introduction}

Thyroid-associated orbitopathy (TAO) is an autoimmune condition of the orbit which is closely associated with Graves' hyperthyroidism, although either condition may exist without the other. It may antedate, coincide with or follow hyperthyroidism (1-10). Assessment of the frequency of the association depends on the method used for detecting TAO; with sensitive methods subclinical TAO can be demonstrated in $70 \%$ of patients with hyperthyroidism. The clinical features of the disorder vary from a mild grittiness of the eyes to severe diplopia, loss of vision and disfiguring proptosis. The most obvious pathological change within the orbit is the enlargement of extraocular muscles (11-13). In most cases microscopy reveals that the muscle fibres are preserved and the increase in muscle bulk reflects changes in the connective tissue: fibroblasts are very numerous, there is lymphocyte infiltration, an excessive deposition of collagen and of glycosaminoglycans (gag) which lead to interstitial oedema (14-22). A role for cytokines in TAO (23) seems likely: it may be that the autoimmune response evokes the local production within the orbit of cytokines which cause fibroblast stimulation and hence the production of collagen and gag (24-28). The muscles most frequently affected are the medial and inferior recti. Functionally, the effect is of tightness or contraction of the muscles, and thus the patient may experience difficulty with upward or lateral gaze. The increased bulk of the muscles and of orbital connective tissue leads to an increase in pressure within the orbit, which results in some cases in proptosis, and in other cases, where the tissues at the apex of the orbit are involved, in optic neuropathy and disc oedema.

There is a natural tendency towards spontaneous improvement: the spontaneous course depicts an active phase which slowly abates, after which an inactive phase ensues (29), which may still be associated with ophthalmic abnormalities. Although sparse, there are histology data to support this idea of active and inactive disease phases $(30,31)$. The orbital tissues are oedematous in patients with early disease, whereas patients with longstanding TAO have fibrous tissues. On histological examination, early disease was associated with a mononuclear cell infiltrate, while in the late stages only dense collagen scar tissue was found. In addition to macrophages and T- and B-lymphocytes, granulated mast cells may be present. Thus, there seems to be consensus that oedema with a lymphocyte infiltrate of the orbital tissues characterizes the active stage, whereas fibrosis can be seen during all stages but is much more abundant in inactive TAO. This natural course has been the basis for the initiation of immunomodulatory therapies (32-36). They are aimed at the oedematous, lymphocyte infiltration and the activated fibroblasts. Medical treatment will only be effective during the active phase and should not be given to patients with inactive TAO. In contrast, it is generally recommended that rehabilitative surgery should only be done on patients with inactive TAO $(37,38)$.

\section{Imaging procedures in TAO}

Differential diagnosis of TAO includes lymphoma, metastasis, tumours of the nasal cavity or sinuses, and fistula of the carotid sinus cavernous. However, the major differential diagnosis of TAO is myositis, a local form of the orbital pseudotumour. This non-specific, inflammatory condition may involve every orbital structure to a different extent. Enlargement of the muscle, including the tendon, is characteristic for this inflammation; the isolated orbital pseudotumour shows no preference for a muscle group. With respect to diagnostic procedures as well as follow-up after specific conservative and/or surgical treatment, imaging with computed tomography (CT), magnetic resonance imaging (MRI), orbital ultrasound (US), and somatostatin receptor scintigraphy with the radiolabelled somatostatin analogue Octreotide ('octreoscan') plays an important role in the interdisciplinary management of subjects with TAO. CT and MRI, especially, show the actual objective morphological findings (39-41), quantitative MRI giving additional information concerning the acuteness or chronicity of the disease. Major morphological diagnostic criteria include a spindle-like spreading of the recti muscles $(>4 \mathrm{~mm})$ without involvement of the tendon, a compression of the optic nerve in the orbital apex (crowded orbital apex syndrome) and the absence of any space occupying intraorbital process. A longer lasting course of the disease may lead to a corresponding impression of the lamina papyracae, the normally parallel configured 
medial wall of the orbit, similar to a spontaneous decompression.

Recently, members of the European Thyroid Association (ETA) were invited to answer a questionnaire to determine how expert thyroidologists assess and treat TAO (42). Eighty-four responses were received from nineteen European countries, representing approximately $60 \%$ of the clinically active ETA members. Marked geographical variation was noted, particularly in the treatment of TAO. Observed consensus was nation-wide rather than Europe-wide. For imaging of TAO, major differences in investigation usage between European countries were registered. CT scans were used by $32 \%$ of German centres, which conducted the most MRI scans (50\%). In Denmark and The Netherlands, 88 and 100\% respectively used CT scans compared with 13 and $0 \%$ for MRI scans. Octreoscans were performed only in Austria, Belgium, Germany, Italy, The Netherlands, and Poland. Eighteen centres used CT plus either MRI or US, 5 used CT and MRI and 5 used octreoscan plus either CT or MRI. All in all, CT scan, MRI, US, and octreoscan were used in $65,34,28$, and $7 \%$ of centres respectively. In the following review, detailed descriptions of the actual imaging techniques and their clinical applications will be discussed.

\section{Computed tomography (CT)}

\section{Technique}

CT can distinguish normal and abnormal structures of different tissue density on the basis of differential X-ray absorption. Orbital fat absorbs X-rays to a lesser degree than water; it is imaged in CT as a black, low-density area that contrasts with the higher-density image of extraocular muscles and the optic nerve (43-45). The presence of orbital fat allows high spatial and density resolution of orbital structures. Inherent tissue differences in the orbit obviate the need for intravenous contrast unless a patient presents with visual loss. After digital recording, data are converted via an arithmetic procedure into different grey scales. In comparison to the isodense brain, tissue such as bone with high absorption values is called hyperdense, while low absorbing tissue such as water or fat are hypodense. Orbital CT scans are routinely performed using 1 - to 2$\mathrm{mm}$ thick sections at 2-mm intervals in the axial plane. Individual volume elements obtained from these axial slices can be reformatted in any plane to produce coronal, sagittal, paraxial, or parasagittal oblique images. In contrast to direct coronal scans, sagittal and coronal reformations avoid high spatial frequency artefacts from dental appliances and other metal implants. Multiplan reformations enable a lesion to be viewed in the optimum anatomic plane and its location to be assessed relative to contiguous orbital, bone, sinus, and central nervous system structures. Axial CT examination of the orbit should be prepared in a line parallel to the infra-orbital-meatal line, a line between the upper part of the external acoustic meatus and the orbital floor, which guarantees images parallel to the orbital axis and a common visualization of the intraorbital course of the optic nerve with the medial muscle in one slice. Modern CT equipment enables application of spiral technique (simultaneous X-ray exposition and defined table movement) of $2 / 3 \mathrm{~mm}$ slice-thickness and distance respectively. A coronary projection perpendicular to the skull base is necessary in order to define the involvement of the inferior and/or superior rectus muscles. During CT examination, one should recognize the lens as being one of the most sensitive organs. In axial examination parallel to the orbital axis, the lens is in the centre and the radiation dosage is comparable to a conventional tomography of the orbit. Depending on the slice thickness $(2-3 \mathrm{~mm})$ and table movement, the total lens dose may vary from 40.3 to $41.5 \mathrm{mSv}$ per slice. The threshold dose for a cataract is the equivalent of a dose of $0.5 \mathrm{~Sv}$ for a single exposure, keeping in mind a latency of up to 25 years after X-ray exposition, but the cumulative effects of the radiation (45) (Fig. 1).

\section{Clinical applications}

Orbital surgeons rely primarily on CT and MRI for diagnosis of orbital disease. In TAO the imaging pattern is relatively characteristic: the extraocular muscles appear to be the primary area of orbital involvement, while others suggest that fat and muscle volume is increased (46-48). The lachrymal gland can occasionally be enlarged. Among patients with TAO, fat volumes as high as $22 \mathrm{ml}$ and muscle volumes as great as $21.5 \mathrm{ml}$ were recorded. The error rate in these measurements was $1 \%-7 \%$ depending on the relative size of the volume measured. Forbes et al. (49-51) found the mean volume of normal extraocular muscles to be $4.69 \mathrm{ml}$ (range $3.66-6.2 \mathrm{ml}$ ) in females and $4.79 \mathrm{ml}(3.07-6.18 \mathrm{ml})$ in males. For orbital fat, the figures were $10.1 \mathrm{ml}(8.2-12.2 \mathrm{ml})$ in females and $11.19(8.6-14 \mathrm{ml})$ in males. Extraocular muscle enlargement can be asymmetric in as many as 30\% of the cases. In a series of 116 patients with Graves' disease, definite enlargement of extraocular muscles was noted in $85 \%$ of cases (52). The inferior rectus was enlarged in $77 \%$, the superior in $51 \%$, and the lateral rectus in $80 \%$ of patients. In another series of $80 \mathrm{CT}$ examinations of TAO patients, the inferior rectus was enlarged in $60 \%$, the medial in $50 \%$, the superior in $40 \%$, and the lateral in $22 \%$ of cases. In a Japanese CT scan study on 349 thyroid patients (53) the inferior rectus was enlarged in $43 \%$, the medial in $38 \%$, the superior in $29 \%$, and the lateral in $16 \%$ of cases. One muscle was enlarged in $31 \%$, two muscles in $25 \%$, three muscles in $24 \%$, and all four recti in $21 \%$ of patients with ocular involvement. In most studies, CT findings have correlated with clinical impressions of the 

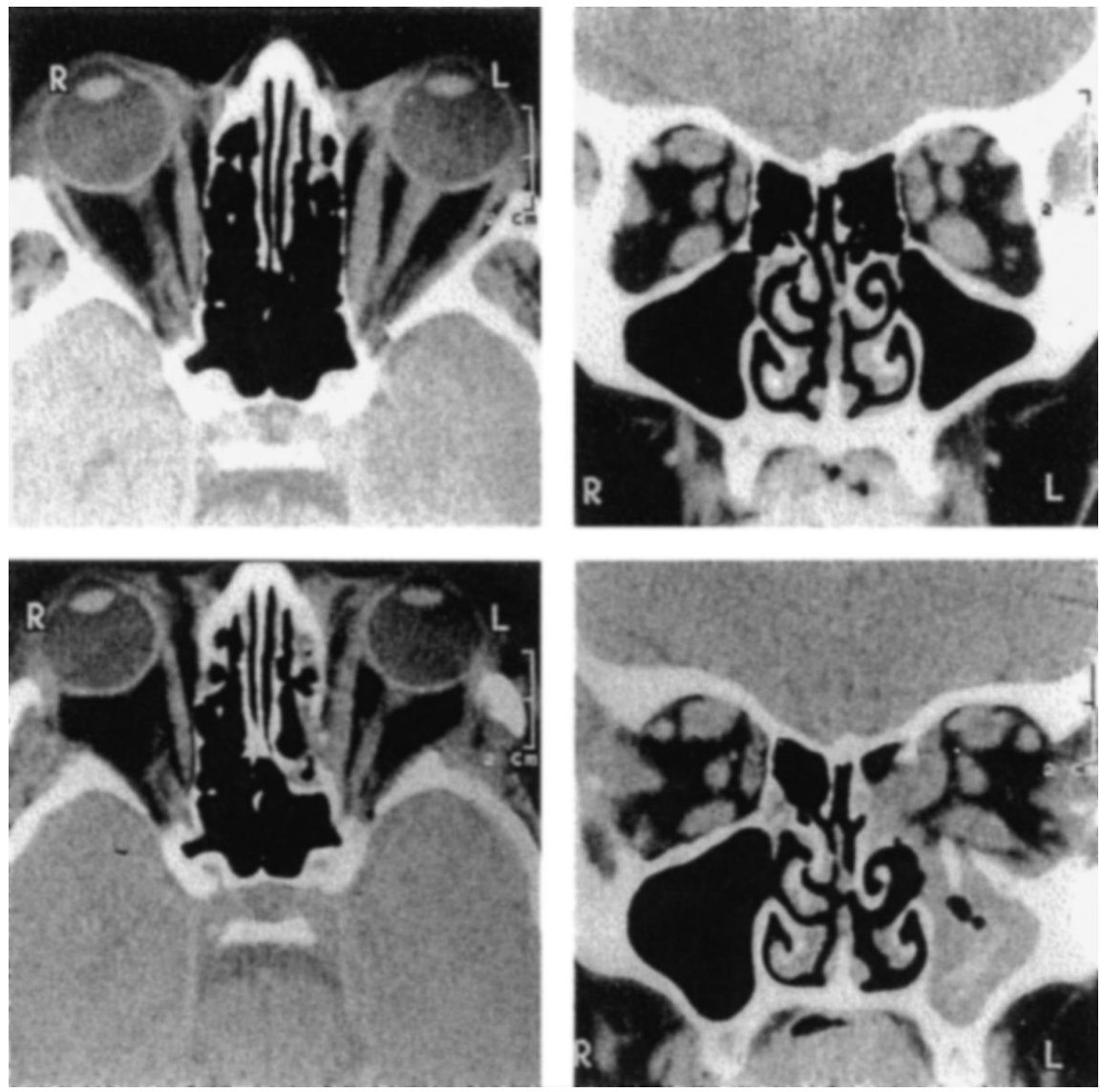

Figure 1 Axial (right panels) and coronal (left panels) CT of a TAO patient before (upper panels) and after (lower panels) orbital decompression surgery.

severity of extraocular muscle enlargement. Bilateral orbital involvement on CT scans is noted in approximately $50-75 \%$ of patients presenting with unilateral eye findings. Unlike patients with orbital myositis or orbital pseudotumour, evidence of muscle involvement on CT of TAO is usually limited to the nontendonous portion of the muscle. Often several muscles are enlarged, especially at the orbital apex. The use of reformation improves delineation of the recti muscle involvement. Nevertheless, in a few TAO patients there is no evidence of an orbital mass; axial CT may demonstrate an enlarged inferior rectus muscle that can simulate an apical neoplasm. CT is also useful to delineate the aetiology of decreased vision. Several investigators have noted that increased extraocular muscle volume or area on CT correlates with compressive optic neuropathy (54-56). The area of the medial rectus muscle on a mid-axial scan also correlated with total muscle volume $(r=0.88)$ and can be used to predict possible optic nerve compression. Other findings that may be noted on CT are a dilated superior ophthalmic vein and abrupt angulations of the posterior muscle belly. An additional sign of nerve compression is intracranial fat prolapse (9; Table 1).
Nevertheless, MR scans show the optic nerve compression better than CT evaluation.

\section{Magnetic resonance imaging (MRI)}

\section{Technique}

Hydrogen nuclei with an odd number of nucleons (protons and neutrons) behave as small magnets or dipoles. Protons are ubiquitous, and their resonance is the basis of MRI techniques $(45,57,58)$. Imaging with MR represents free moving protons of a given tissue, producing energy (read as signals) while returning into their primary position in a high magnetic field after deflection by a high frequency pulse. Bright signals are defined as hyperintensity, while low signal areas are defined as hypointensity to signal void of complete loss of signal. When the orbit is placed in a magnetic field there is a net alignment of protons. When exposed to radio-frequency (RF) excitation there is a reversal of polarity of some of these hydrogen nuclei, and they are raised to a higher energy level. When the RF is terminated, the protons return to the baseline polarity, and the emitted energy can be measured. This is called 
Table 1 Computed tomography.

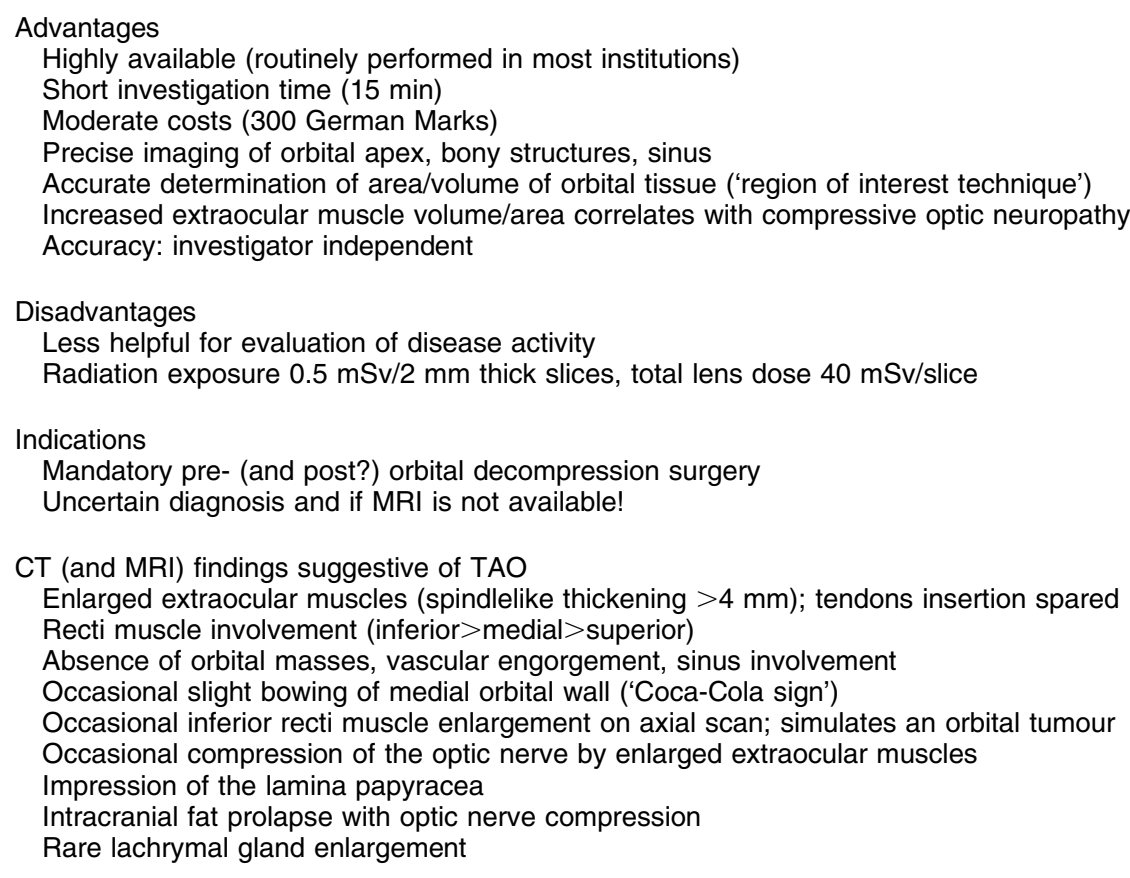

T1 relaxation (T1) and is best measured immediately after RF termination. Exposure to RF excitation also initiates a uniform synchronous precession, or spin, among the protons. When the RF is terminated, this precession diminishes at differing rates for protons in different molecular environments. The energy emission measured from this event is called $\mathrm{T} 2$ relaxation time (T2). Since the RF-initiated events depend on the frequency and magnetic field strength, the location of these events in three-dimensional space can be determined by imposing a gradient (approximately 0.1 tesla $(\mathrm{T})$ per centimetre on the magnetic field and varying the RF). Optimal current strength for clinical imaging is $1.5 \mathrm{~T}$, currently used scanners range from 0.15-4.5 T. Orbital anatomic detail is obtained with surface coils and thin section scans. A basic rule for MRI is that $\mathrm{T} 1$ weighted $(\mathrm{T} 1 \mathrm{w})$ images are best for anatomic structure, while $\mathrm{T} 2 \mathrm{w}$ sequences give more information about the different tissue composition. The advantage of MRI is the ability to view several (axial, coronal, sagital) angles without movement of the patient. T1w axial and coronal sequences give an overview of the extent of the disease, concerning globe proptosis and involvement of the different recti muscles. In a few cases, application of gadolinium, the MRcontrast agent may help in better delineation of fatty degeneration, when applied with fat suppressed sequences. Fat suppression enables the differentiation of the intense signal enhancement of the recti muscles, which otherwise would look as intense as fat tissue. Slice thickness should not be less than $3 \mathrm{~mm}$. Fat suppression performed in the coronal view increase MRI sensitivity for different proton concentrations. Orbital fat that has a short $\mathrm{T} 1$ and medium $\mathrm{T} 2$ will produce a strong signal. Muscle is intermediate in signal intensity; vitreous has long $\mathrm{T} 1$ and $\mathrm{T} 2$, cortical bone is displayed as black as there is no mobile hydrogen and therefore no MR signal. Soft-tissue spatial resolution obtainable with MRI is greater than that obtained with high-resolution CT and shows greater tissue contrast (Fig. 2).

\section{Clinical applications}

MRI estimates disease activity although cost and availability are current limitations of this modality. Pulse sequences that examine T2 can estimate the water content of tissues. When examining the extraocular muscles, normal T2 might imply burned out, fibrotic disease with low water content, whereas prolonged T2 might suggest ongoing inflammation with tissue oedema possibly amenable to immunosuppression or radiotherapy. Using a $0.28 \mathrm{~T}$ magnet, a correlation between $\mathrm{T} 2$ and response to treatment was reported. Comparing the extraocular muscle signal to control tissues, two studies found that a high T2 was associated with disease activity $(59,60)$. A significant correlation between $\mathrm{T} 2$ of eye muscle and that of orbital connective tissue was demonstrated, indicating that a common mechanism may be involved in the pathogenesis of the muscle and connective tissue components of TAO. MRI of optic nerves also demonstrates 

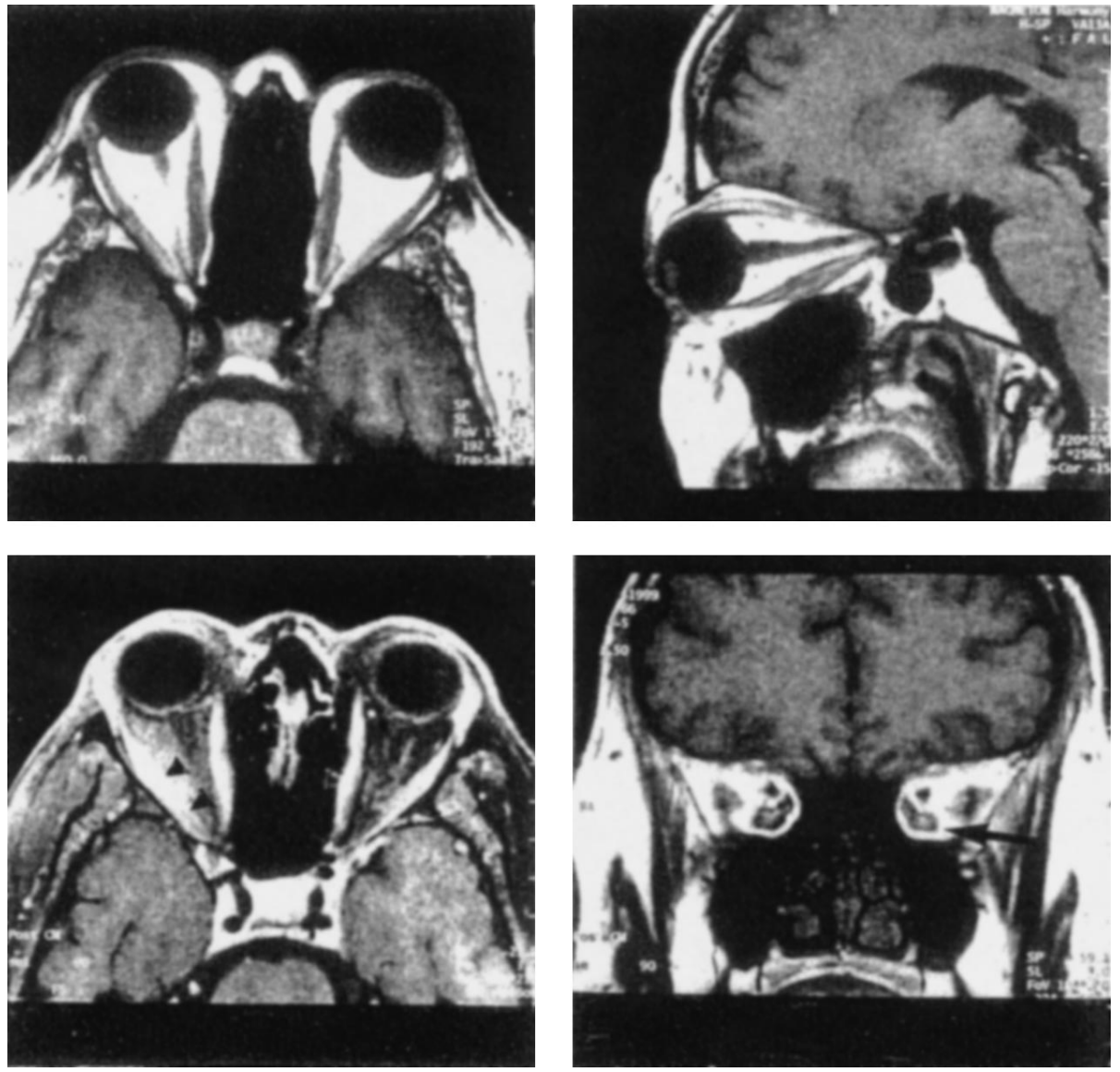

Figure $2 \mathrm{MRI}$ of a TAO patient with fatty degeneration of all extraocular recti muscles. Upper left: axial T1w image, showing symmetric proptosis with suspected fatty degeneration of the right lateral recti muscle; lower left: the corresponding contrast enhanced view (with fat saturation) where the hypointensity (arrowheads) confirms the diagnosis; upper right: the T1w parasagitttal view (parallel to the course of the optic nerve) demonstrates the high fat signal in the superior and inferior recti muscles of the right orbit; lower right: T1w coronal view with fatty inferior recti muscle, especially on the left (arrow).

Table 2 Magnetic resonance imaging.

\section{Advantages}

Tissue differentiation

Lack of ionising radiation

High quality orbital anatomic detail imaging obtained with surface coils and thin section scans

T2 relaxation time: sensitive for demonstrating interstitial oedema within recti eye muscles and oedema in orbital fat. Compared to

$\mathrm{CT}, \mathrm{MRI}$ is more sensitive to alteration in water content or hydrogen concentration processes

Accuracy: investigator independent

High negative predictive value

\section{Disadvantages}

Less helpful for evaluation of bony structures

Expensive (500 German Marks)

Investigation time 45-60 min

'Claustrophobia'

\section{Indications}

Patient with thyroid disease and decreased vision: MR scans with fat saturation and gadolinium (contrast agent) are indicated. MRI can detect compressive optic nerve changes and differentiate them from non compressive neuropathy

TAO in which it is uncertain whether medical or surgical intervention is appropriate: better delineation of inflammatory from fibrotic disease than clinical evaluation

Uncertain diagnosis (thyroid vs other cause of orbital disease)

Serial investigations to monitor the progress or response to treatment 
compression better than CT, and delineation of compressive optic neuropathy is easier with MRI than CT (61; Table 2).

Infiltration of orbital tissue by lymphocytes leads to fibroblast stimulation and consequently increased gag production. By binding large amounts of water, gag cause oedema, resulting in an increased volume. Therefore, increased water content of thickened extraocular muscles is most likely the cause of elevated T2. Reversibility of thickness and relaxation times in muscles with primarily elevated $\mathrm{T} 2$ can be explained as a therapy-induced decrease of water content. In numerous studies, TAO patients with primarily elevated $\mathrm{T} 2$ of extraocular muscles showed better response to medical therapy with respect to change in muscle thickening than those with primarily normal T2 (62). In a controlled study, muscles with primarily elevated $\mathrm{T} 2$ showed marked reduction of $\mathrm{T} 2$ by $30 \%$, and muscle area by $32 \%$ after immunosuppressive therapy (58). At the end of therapy, a reduction of more than $30 \%$ or normalization of muscle area occurred in 50\% of muscles with primarily enhanced T2. In contrast, thickened muscles with primarily normal T2 only exhibited a slight decrease of muscle area. The predicted probability of response to treatment increased with increased mean $\mathrm{T} 2$ of extraocular muscles prior to therapy (63). Of the subjects undergoing medical treatment, only those with markedly prolonged T2 showed an impressive response. Recently, long-term follow-up data of a large number of patients with severe TAO who were monitored by MRI before and after therapy with the immunosuppressive drug, Ciclosporin, were reported (64). In these patients there was a correlation between decrease in $\mathrm{T} 2$ of the rectus muscles and response to Ciclosporin treatment. In addition, the infiltrative eye signs improved in correlation with T2, muscle thickness and intraocular pressure. Thus, the major result of these studies is the relationship between response to therapy and pretherapeutic T2 times. Therefore, measurement of elevated T2 might play a role in the prediction of the reversibility of muscle thickening and favours the choice of antiinflammatory therapy regimens in these patients. T2 of the rectus muscles also significantly correlated with orbital accumulation of the radiolabelled Octreotide in untreated subjects with active TAO, suggesting similar prognostic and therapeutic implications (65).

\section{Ultrasound (US)}

\section{Technique}

US is usually performed with A-scan, B-scan, or both (66-69). Using a standardized unit, A-scan is used to assess tissue characteristics based upon reflected acoustic waves. Reflectivity in the extraocular muscles may change as a function of tissue oedema and cellular infiltration. For example, a low reflectivity on A-scan may be a valid means of assessing activity of disease. Immersion B-scan is the easiest image for the nonultrasonographer to visualize and is also most useful for determining if individual recti muscles are enlarged (measuring the maximum diameter of the eye muscles). Maximal muscle thickness above the 95th percentile, or a variance of more than $0.5 \mathrm{~mm}$ between the same muscles in the two orbits, is consistent with the diagnosis of TAO. The probe is directed towards the widest portion of the muscle. The width of the echographic envelope can be measured directly. In the hands of an experienced orbital ultrasonographer, the test is relatively reliable, accessible, and inexpensive. Byrne et al. (70) have completed a careful assessment of extraocular muscle dimensions as measured by A- and B-mode echography using modern instrumentation. Healthy extraocular muscles ranged in diameter from $2.6 \pm 0.5 \mathrm{~mm}$ for the inferior rectus to $5.3 \pm 0.7 \mathrm{~mm}$ for the levator complex. Diameter of contralateral muscles varied by as much as $0.8 \mathrm{~mm}$. On the other hand, a wide range of normal values for the different eye muscles has been reported. The nongeometric pattern of muscle enlargement can produce measurement errors on repeat US evaluations. When US measurements of muscle thickness were compared with MRI data, the accuracy of US was significantly less, and this problem was worse in muscles other than the inferior rectus (71). The authors compared A-mode with MRI in 20 patients. Maximum transverse diameter of each rectus muscle was determined by each method in 39 orbits. Linear regression of individual US against MRI showed coefficients of determination moderate (0.29) for inferior recti muscles and low (0.11) for other recti muscles. Further errors in using a cross-sectional approach are derived from the oval rather than round cross section of the muscles, and because the maximum thickness occurs only over a limited anteroposterior distance in the orbit. This makes it difficult for the ultrasonographer to orient the beam so that it is exactly perpendicular to the muscle at the point of interest. These physical limitations of the US approach may account for the wide difference in published norms for transverse diameter of the recti. For the medial rectus muscle these range from the 95 th percentile values of 6.08 to $<3.6$ indicating not only the inherent variability of US measurements but also differences in technique between investigators. The source of this discrepancy is uncertain, since both techniques are subject to imaging artefacts. In the high-resolution MR images, the muscles had a teardrop shape; perhaps the widest part of the extraocular muscle is not consistently imaged with the US technique. Thus, those operators experienced in the performance and interpretation of the study do the best US examinations. The relative rarity of experienced ultrasonographers also limits the utility of this method. 
Table 3 Ultrasound.

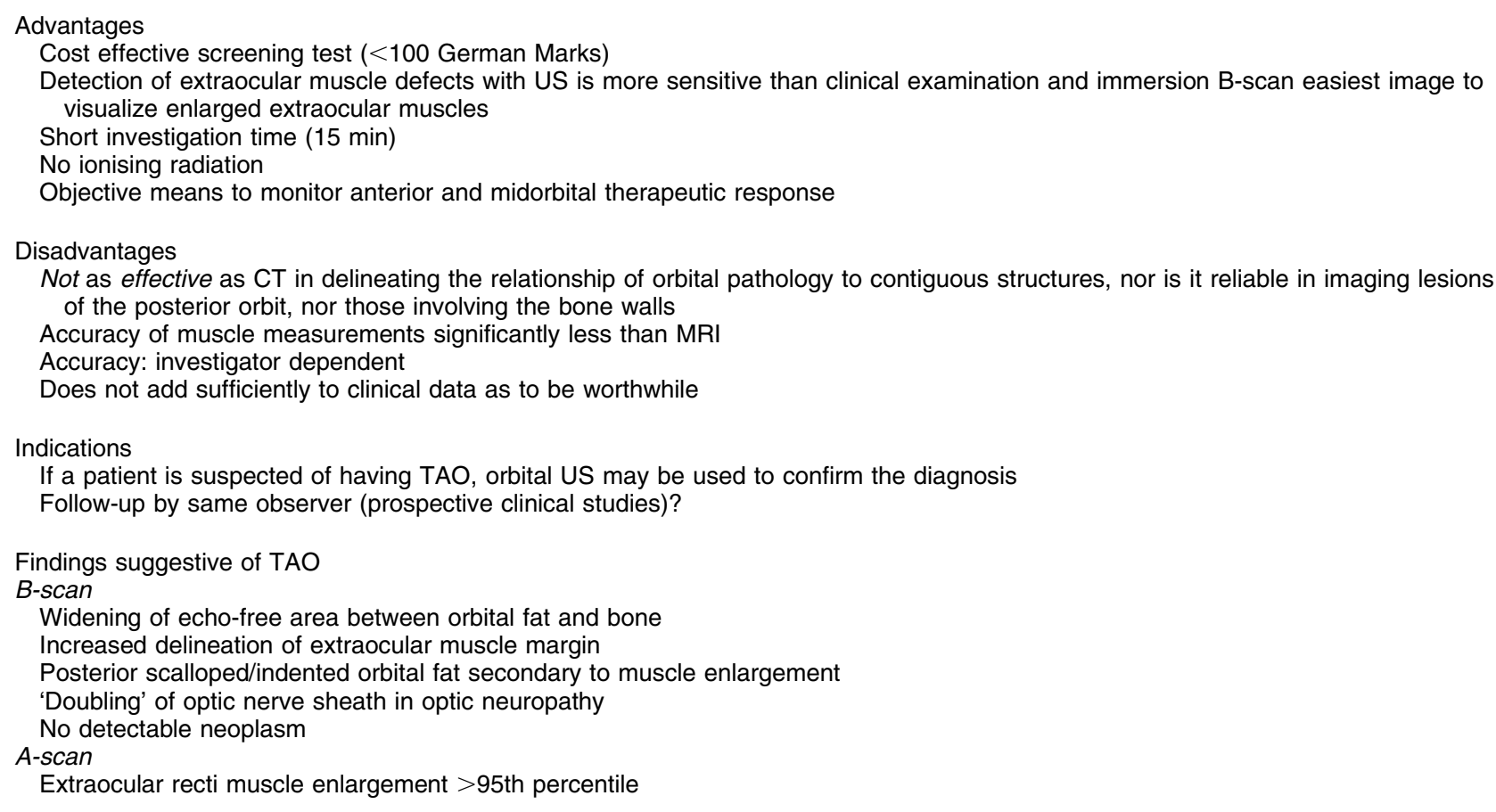

\section{Clinical applications}

In clinical practice, US is a cost-effective screening test for the evaluation of TAO patients (Table 3). The detection of extraocular muscle defects with US is more sensitive than is clinical examination (66). In one study, while enlargement of extraocular muscles was only noted clinically in $12 \%$ of patients, on US this was detected in $95 \%$ of cases. In a further study, 20 of 32 patients $(63 \%)$ without clinical TAO had B-scan evidence of muscle enlargement. Enlarged optic nerves are rarely noted, usually in association with optic neuropathy. US is also an objective means for monitoring anterior and midorbital therapeutic response, although it does not add to clinical data sufficiently to be worthwhile. Erickson et al. (72) have proposed serial US as a suitable method to follow the changes after radiotherapy. With combined A- and B-scan, they claimed that there was $99 \%$ accuracy in diagnosing TAO and that the muscle thickness can be ascertained with an accuracy of $\pm 0.75 \mathrm{~mm}$. On the other hand, there is sufficient variability in A-scan data to limit its patent use to determine whether fibrosis has developed. Internal reflectivity of the sound beam was found to be low in subjects with active TAO, presumably due to oedema, whereas the reflectivity was high and irregular in inactive patients, due to fibrotic echogenic scar tissue. In a preliminary study in 16 patients (73) the method seemed promising: positive and negative predictive values (PV) of 73 and 100\% respectively were noted (reflectivity of $40 \%$ or less). However, after testing a further 56 TAO patients, results were rather disappointing: negative PV being only 60\% (3).

Orbital MRI and US were performed in 43 patients with TAO with recently developed diplopia (74). No correlation was found between the diameters of 233 extraocular muscles measured by MRI and US. For each of the four muscles, there was a diameter above which US was always unreliable. Neither US, nor any combination of 11 clinical and laboratory parameters provided the degree of information on muscles and connective tissue that was obtainable by MRI. Finally, although orbital US has many advantages, it cannot effectively display the muscles at the apex of the orbit where compression of the optic nerve commonly occurs. US is not as effective as CT in delineating the relationship of orbital pathology to contiguous structures, nor is it reliable in imaging lesions of either the posterior orbit, or those involving the bone walls (75).

Colour Doppler studies have also been performed in TAO. Colour Doppler imaging makes it possible to assess blood flow velocity of orbital vessels and allows detection of changes in the perfusion of orbital arteries and veins. At our institution, 23 subjects with TAO were examined using colour Doppler (76). Compared with controls, flow velocity in the right ophthalmic artery was markedly enhanced in subjects with clinically active TAO. Furthermore, maximal blood flow velocity in the superior orbital vein was significantly decreased in TAO subjects versus controls and reduced venous outflow in the superior orbital vein correlated with the severity of TAO. Thus, reduced 
venous outflow may contribute to proptosis by creating per venous oedema and consequent swelling of orbital fat.

\section{Octreoscan}

\section{Technique}

Octreotide, a somatostatin (SM) analogue labelled with indium has been used to localize tumours which possess membrane receptors for SM in vivo (77-80) and to predict the inhibitory effect of Octreotide on hormone secretion by the tumours. By applying octreoscan, accumulation of the radionuclide was also detected both in the thyroid and orbit of patients with Graves' disease. Radionuclide accumulation is most probably due to the presence of activated SM receptors bearing lymphocytes. Alternative explanations are binding to receptors on other cell types (myoblasts, fibroblasts, endothelial cells) or local blood pooling due to venous stasis by the orbital inflammation. Wide differences exist regarding the administered dose of radionuclide, the time interval after injection for determining the orbital uptake, the selection of orbital slices for quantification of the orbital uptake, and the method of correction for background radioactivity (81-84). Earlier studies used rather large doses and preferred to measure orbital uptake 24 h postinjection, while later studies administered lower doses and measured orbital uptake only $2 \mathrm{~h}$ postinjection, arguing that the low dose decreases the radiation burden and the cost of examination. Nevertheless, a low dose might cause problems in count statistics, and at $2 \mathrm{~h}$ postinjection $12 \%$ of the dose is still in the blood pool causing high background uptake. Furthermore, the radiation burden received from a high dose of $222 \mathrm{Mbq}$ is $16 \mathrm{mSV}$, in the same order as that from chest CT or angiography. The inference is that for discrimination purposes a 4-h time interval is preferred when a low dose is chosen. However, any remaining orbital radioactivity $24 \mathrm{~h}$ after administering a high dose might represent a greater degree of specific tissue binding, possibly enhancing both the differential diagnostic and predictive value of octreoscan. Another technical problem is the selection of regions of interest (ROI), which may result in considerable intra- and inter-observer variation. Single photon emission computed tomography (SPECT) images are obviously required and measuring uptake in a number of orbital slices from SPECT images is of great advantage in the quantification of the results. Since parts of the radioactivity in the left temporal skull area may be due to uptake in the parotid gland, background measurements in the occipital skull area are recommended. The brain itself is used to measure background but for most investigators it seems less suitable to correct for blood pool radioactivity (80).

Recently, analysis of inter-/intra-observer variance and reproducibility in the evaluation of orbital SPECT images was performed (85). For the right and the left orbit, the inter-observer variance proportion was 90 and $79 \%$ respectively, whereas intra-observer variance partition was 10 and $21 \%$ respectively. The overall reliability was $84 \%$, intra-observer reliability was $88-$ $98 \%$, and observer reproducibility was 94\%. Evaluations of orbital octreoscan have to be carried out by the same experienced observer, leading to comparable data. At our institution, an automatic and quantitative computerized technique has been established. Standardized 3 dimensional (3-D) orbital volumes of interest (VOI) were generated on MRI of normal subjects (86). After position-orientation on a standard MRI data set, SPECT data were evaluated by automatic superimposition with the size-adapted VOIs. Radionuclide activity was measured as uptake (\%) of injected tracer activity. Advantages of this new 3-D technique are the accurate quantitative determination of the orbital uptake as well as the independence of observer variation.

Table 4 Octreoscan

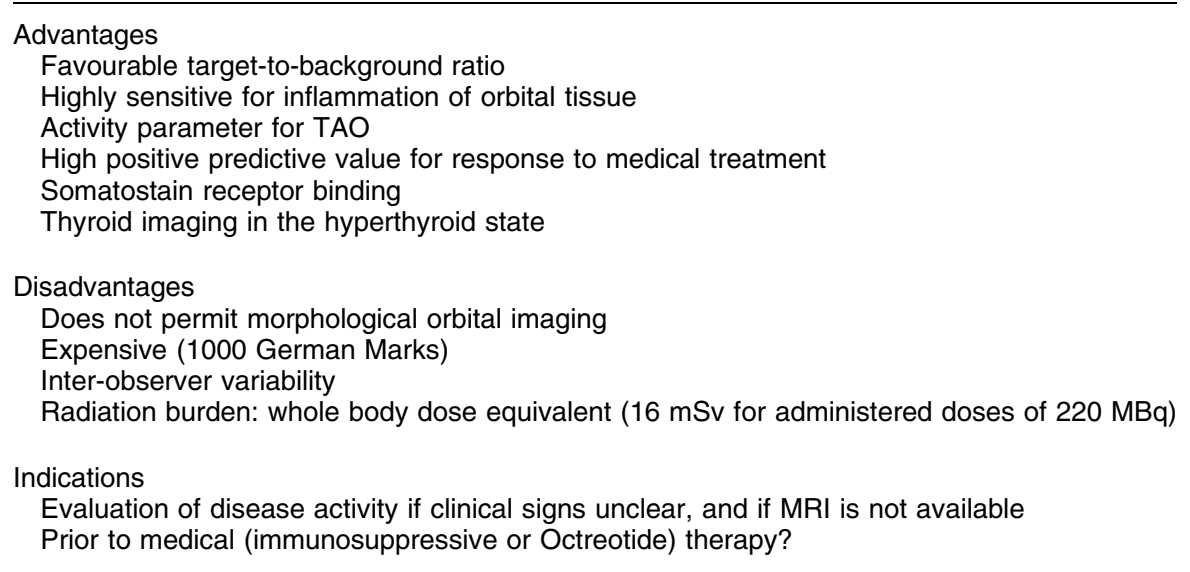




\section{Clinical applications}

Cross sectional and longitudinal studies in patients with Graves' disease showed that a high uptake of radiolabelled Octreotide correlated with orbital inflammation and active hyperthyroidism (65, 87-89) (Table 4). In vivo imaging of SM receptors by the radionuclide as a sensitive nuclear medicine technique and a high positive predictive value was able to select those patients who might benefit from treatment with immunosuppressive agents. Furthermore, in the followup of these patients, the change in Octreotide binding during medical therapy points to the fact that this type of scanning can be used to monitor the effects of treatment. Krenning and colleagues have also performed octreoscan in patients with Graves' disease and in controls (90). Thyroidal Octreotide accumulation was increased in thyrotoxicosis, and was almost absent after radioiodine-induced hypothyroidism. A correlation between thyroidal Octreotide accumulation and free thyroxine (disease expression) and thyroid binding-inhibiting immunoglobulins (disease activity) was present in untreated Graves' disease. Orbital Octreotide uptake was significantly higher in patients with active TAO compared with those with slight TAO, and enhanced orbital radionuclide activity decreased after therapy. A correlation between orbital Octreotide uptake and the clinical score (disease activity) and total eye score (disease expression) was noted. High pretreatment orbital uptake correlated with a response to radiotherapy. Results of octreoscan in TAO patients correlated with clinical activity scores as well as with T2 of extraocular recti muscles $(65,91)$. The ability of this scintigraphic method to detect active eye involvement as compared with a purely clinical evaluation was also looked at, and a correlation between both methods was noted. All patients with highly active TAO were clearly identified by both procedures. Positive scans were also seen even under steroid therapy indicating persistent active disease, whereas patients with disease of long duration were negative. Moncayo et al. (92) reported that successful immunoglobulin therapy significantly decreased inflammatory eye signs, clinical activity of the disease, and orbital radionuclide accumulation.

Octreotide has been reported to have a beneficial effect in TAO, probably by modulating lymphocyte responsiveness and gag production. In a placebocontrolled study, 12 TAO patients received $0.3 \mathrm{mg}$ Octreotide daily for 12 weeks (93). The seven patients who showed amelioration in ocular manifestation had positive orbital scans, while patients who did not respond had negative ones. None of the Graves' patients without clinically apparent TAO had a positive octreoscan. Successful therapy with SM analogues (94) was associated with a fall in orbital uptake. Thus, octreoscan is mainly indicated to select TAO patients who will benefit from immunomodulation. To this end, one must know the predictive value of octreoscan for the outcome of immunosuppressive treatment. In one study, when a clinical improvement of TAO was considered after 3 months of Octreotide therapy, the positive and negative predictive values of octreoscan were 87 and $100 \%$ respectively. When Lanreotide was used, the positive predictive value was 90\% (95). In a recent paper (88), 14 of 16 TAO patients with an orbit/ brain radionuclide ratio $>10$ at $4 \mathrm{~h}$ postinjection, responded to steroid- or radio-therapy, compared with none of four patients with a ratio $<10$. Regarding the evaluation of TAO activity, it was found that when a ratio $>10$ was chosen as the cut-off point, a sensitivity of $94 \%$ and a specificity of $100 \%$ were given (Table 5).

\section{Conclusions}

Orbital US, CT, as well as MRI are commonly used as imaging techniques to demonstrate pathological changes in ocular adnexa of patients with TAO. Low cost, short time of investigation and lack of radiation characterize orbital US, a technique which ought to be more widely used. Thus, where available, orbital US may be useful in diagnosis and also in evaluating the severity of eye muscle involvement. Nevertheless, a

Table 5 Prediction of outcome of immunosuppressive therapy for TAO subjects.

\begin{tabular}{|c|c|c|c|c|}
\hline & \multicolumn{2}{|c|}{ Predictive value (\%) } & \multirow[b]{2}{*}{ Number of patients } & \multirow[b]{2}{*}{ Reference } \\
\hline & Positive & Negative & & \\
\hline \multicolumn{5}{|l|}{ Orbital MRI } \\
\hline $\mathrm{T} 2>128 \mathrm{~ms}$ & 50 & 75 & 18 & 58 \\
\hline Signal intensity ratio $>1.8$ & 69 & 86 & 23 & 59 \\
\hline \multicolumn{5}{|l|}{ Orbital ultrasound } \\
\hline Reflectivity $<40 \%$ & 73 & 100 & 16 & 73 \\
\hline Reflectivity $<40 \%$ & 85 & 60 & 56 & 3 \\
\hline \multicolumn{5}{|l|}{ Orbital octreoscan } \\
\hline Orbit/brain ratio $>10$ & 88 & 100 & 40 & 87 \\
\hline Orbit/skull ratio $>1.5$ & 87 & 100 & 12 & 93 \\
\hline Orbit/occipital ratio >1.85 & 92 & 70 & 22 & 91 \\
\hline
\end{tabular}


clear differentiation regarding disease activity is not possible, nor is an evaluation of retrobulbar tissue precise enough. The more generally available techniques of CT or MRI are particularly useful for diagnostic purposes where other orbital pathology may need to be excluded; they also usefully demonstrate optic nerve compression at the apex of the orbit. When performing CT, differentiation between active and inactive TAO is not possible. On the other hand, short investigation time, precise imaging of the orbital apex and moderate costs are advantages of this procedure. Furthermore, with the help of a computerized program, the orbital adipose/connective tissue volume can be accurately determined. CT delivers a significant radiation dose to the lens, which if repeated constitutes a risk for cataract development. For this reason MRI is preferable, particularly if repeat scans are required to assess response to treatment. The possibility of tissue differentiation, lack of ionising radiation, and capability of multiple plane imaging uniquely suit MRI for eye studies. Although sensitive in demonstrating interstitial oedema within the recti muscles in patients with active disease, as well as providing a good predictive value with respect to immunosuppressive therapy, quantitative MRI with T1/T2 measurement is also an expensive method and is non-specific for the orbital changes in TAO. Furthermore, the time of investigation, $45 \mathrm{~min}$, is long.

Because of a favourable target-to-background ratio, octreoscan carries a high sensitivity and may be regarded as a semi-objective tool in the evaluation of patients with Graves' orbital and thyroidal disease, both at the initial stages as well as during treatment. A positive orbital octreoscan indicates clinically active TAO in which immunosuppressive treatment might be of therapeutic benefit. However, the following limitations restrict the widespread use of this technique. First, it is an expensive method with a non-negligible radiation burden. Secondly, it is non-specific, i.e. positive octreoscans may be obtained in patients with orbital diseases such as myositis and lymphoma. Thirdly, octreoscan does not permit detailed orbital imaging or evaluation of eye muscle swelling. Finally, in routine clinical practice, although time consuming, measurements of orbit/brain radionuclide ratios and T2-times (MRI) are definitely necessary to provide high accuracy for both procedures. To conclude, in unclear cases of proptosis or recently developed diplopia, prior to orbital decompression surgery, in the case of non-response to a conservative anti-inflammatory treatment or if, for any other reason, imaging is needed in subjects with TAO, MRI is the imaging method of choice.

\section{References}

1 Bartalena L, Pinchera A \& Marcocci C. Management of Graves' ophthalmopathy: reality and perspectives. Endocrine Review 2000 21 168-199.
2 Weetman A. Medical progress: Graves' disease. New England Journal of Medicine 2000343 1236-1248.

3 Prummel MF, Wiersinga WM \& Mourits MP. Assessment of disease activity of Graves' ophthalmopathy. In Recent Developments in Graves' Ophthalmopathy, edn 1, ch 4, pp 59-79. Ed MF Prummel. Boston/Dordrecht/London: Kluwer Publishers, 2000.

4 Wiersinga WM. Graves' ophthalmopathy. Thyroid International 19973 3-15.

5 Perros P \& Kendall-Taylor P. Natural history of thyroid eye disease. Thyroid $1998 \mathbf{8} 423-425$.

6 Kendall-Taylor P \& Perros P. Clinical presentation of thyroidassociated orbitopathy. Thyroid $1998 \mathbf{8} 427-428$.

7 van der Gaag R, Schmidt ED \& Koorneef L. Retrobulbar histology and immunohistochemistry in endocrine ophthalmopathy. In Endocrine Ophthalmopathy. Molecular, Immunological and Clinical Aspects, edn 1, ch 1, pp 1-10. Ed GJ Kahaly. Basel: Karger Publishers, 1993.

8 Bartley GB \& Gorman CA. Diagnostic criteria for Graves' ophthalmopathy. American Journal of Ophthalmology 1996119 792-795.

9 Char DH. Pathogenesis and pathophysiology of thyroid ophthalmopathy. In Thyroid Eye Disease, edn 3, ch 6, pp 113-141. Ed CH Char. Boston: Butterworth-Heinemann, 1997.

10 Kahaly GJ, Böckmann H, Beyer J \& Bischoff S. Longterm observation of endocrine ophthalmopathy and retrospective appraisal of therapeutic measures. Journal of Endocrinological Investigation 199013 287-293.

11 Burch HB \& Wartofsky L. Graves' ophthalmopathy: current concepts regarding pathogenesis and management. Endocrine Review 199314 747-793.

12 Bahn RS \& Heufelder AE. Pathogenesis of Graves' ophthalmopathy. New England Journal of Medicine 1993329 1468-1475.

13 Heufelder AE. Retro-orbital autoimmunity. Bailliere's Clinics in Endocrinology and Metabolism 199711 499-520.

14 Wall JR, Salvi M, Bernard NF, Boucher A \& Haegert D. Thyroidassociated ophthalmopathy - a model for the association of organ-specific autoimmune disorders. Immunology Today 1991 12 150-153.

15 Rapaport B, Alsabeh R, Aftergood D \& McLachlan SM. Elephantiasic pretibial myxedema: insight into and a hypothesis regarding the pathogenesis of the extrathyroidal manifestations of Graves' disease. Thyroid 200010 685-692.

16 Riley FC. Orbital pathology in Graves' disease. Mayo Clinic Procedures $197247975-979$.

17 Kahaly GJ, Hansen C, Felke B \& Dienes HP. Immunohistochemical staining of retrobulbar adipose tissue in Graves' ophthalmopathy. Clinical Immunology Immunopathology 199473 53-62.

18 Otto E, Ochs K, Leyendecker E, Gentsch A \& Kahaly GJ. Autoimmune endocrine ophthalmopathy and retrobulbar antigens. Hormone Metabolic Research 199527 533-538.

19 Otto E, Förster G, Kuhlemann K, Hansen C \& Kahaly GJ. TSH receptor in endocrine autoimmunity. Clinical Experimental Rheumatology 199614 77-84.

20 Otto EA, Ochs K, Hansen C, Wall JR \& Kahaly GJ. Orbital tissuederived T lymphocytes from patients with Graves' ophthalmopathy recognize autologous orbital antigens. Journal of Clinical Endocrinology and Metabolism 199681 3045-3050.

21 Kahaly GJ, Otto E, Förster G, Kuhlemann K, Olivari N, Beyer J et al. $\mathrm{T}$ cells and orbital connective tissue in endocrine orbitopathy. Experimental Clinical Endocrinology Diabetes 1996104 79-83.

22 Förster G, Otto E, Hansen C, Ochs K \& Kahaly GJ. Analysis of orbital $\mathrm{T}$ cells in thyroid-associated ophthalmopathy. Clinical Experimental Immunology 1998112 427-434.

23 Natt N \& Bahn RS. Cytokines in the evolution of Graves' ophthalmopathy. Autoimmunity 199726 129-136.

24 Kahaly G, Schuler M, Sewell AC, Bernard G, Beyer J \& Krause U. Urinary glycosaminoglycans in Graves' ophthalmopathy. Clinical Endocrinology 199033 35-44.

25 Hansen C, Otto E, Kuhlemann K, Förster G \& Kahaly GJ. Glycosaminoglycans in autoimmunity. Clinical Experimental Rheumatology 199614 59-68. 
26 Hansen C, Fraiture B, Rouhi R, Otto E, Förster G \& Kahaly GJ. HPLC glycosaminoglycan analysis in patients with Graves' disease. Clinical Science 199792 511-517.

27 Kahaly GJ, Förster G \& Hansen C. Glycosaminoglycans in thyroid eye disease. Thyroid $1998 \mathbf{8} 429-432$.

28 Hansen C, Rouhi R, Förster G \& Kahaly GJ. Increased sulfatation of orbital glycosaminoglycans in Graves' ophthalmopathy. Journal of Clinical Endocrinology and Metabolism $1999 \mathbf{8 4}$ 1409-1413.

29 Hales IB \& Rundle FF. Ocular changes in Graves' disease. A longterm follow-up study. Quarterly Journal of Medicine 196029113 126.

30 Naffziger HC. Pathologic changes in the orbit in progressive exophthalmos. Archives of Ophthalmology 19339 1-12.

31 Talstedt L \& Norberg R. Immunohistochemical staining of normal and Graves' extraocular muscle. Investigative Ophthalmology Visual Science 198829 175-184.

32 Kahaly GJ, Schrezenmeir J, Krause U, Schweikert P, Meuer S, Dennebaum U et al. Ciclosporin and prednisone vs prednisone in treatment of Graves' ophthalmopathy: a controlled, randomized and prospective study. European Journal of Clinical Investigation $198616415-422$.

33 Kahaly GJ, Pitz S, Müller-Forell W \& Hommel G. Randomized trial of intravenous immunoglobulins vs prednisolone in Graves ophthalmopathy. Clinical Experimental Immunology $1996 \mathbf{1 0 6}$ 197-202.

34 Kahaly GJ, Roesler HP, Kutzner J, Pitz S, Müller-Forell W, Beyer J et al. Radiotherapy for thyroid-associated orbitopathy. Experimental Clinical Endocrinology Diabetes 1999107 201207.

35 Kahaly GJ, Roesler HP, Pitz S \& Hommel G. Low vs high-dose radiotherapy for Graves' ophthalmopathy: a randomized, singleblind trial. Journal of Clinical Endocrinology and Metabolism 2000 85 102-108.

36 Kahaly GJ, Gorman CA, Kal KB, Mourits MP, Pinchera A, Tan TS et al. Radiotherapy for Graves' ophthalmopathy. In Recent Developments in Graves' Ophthalmopathy, edn 1, ch 8, pp 115131. Ed MF Prummel. Boston/Dordrecht/London: Kluwer Publishers, 2000.

37 Mann WJ, Kahaly GJ, Lieb W \& Amedee RG. Orbital decompression for endocrine ophthalmopathy: the endonasal approach. American Journal of Rhinology 19948 123-127.

38 Mann WJ, Kahaly GJ, Pitz S, Bumb P, Müller-Forell W, Krummenauer $\mathrm{F}$ et al. Decompression surgery for thyroidassociated orbitopathy - a ten year experience. Experimental Clinical Endocrinology Diabetes 1999107 212-213.

39 Kahaly GJ. New imaging procedures in thyroid-associated ophthalmopathy. Orbit 199615 165-175.

40 Flanders AE, Mafee MF, Rao VM \& Choi KH. CT characteristics of orbital pseudotumor and other orbital inflammatory processes. Journal of Computed Assisted Tomography 198913 40-47.

41 Gorman CA. The measurement of change in Graves' ophthalmopathy. Thyroid $1998 \mathbf{8} 539-543$.

42 Weetman AP \& Wiersinga WM. Current management of thyroidassociated ophthalmopathy in Europe. Results of an international survey. Clinical Endocrinology 199849 21-28.

43 Casper DS, Chi TL \& Trokel SL. Orbital Disease, Imaging and Analysis, edn 1. Stuttgart: Thieme, 1993.

44 Peyster RG \& Hoover ED. Graves' orbitopathy. In Computerized Tomography in Orbital Diseases and Neuroopthalmology, edn 1, ch 3 , pp 97-114. Chicago: Year Book Medical Publisher, 1984.

45 Müller-Forell W, Pitz S, Mann W \& Kahaly GJ. Neuroradiological diagnosis of thyroid-associated orbitopathy. Experimental Clinical Endocrinology Diabetes 1999107 177-183.

46 Trokel L \& Jacobiec FA. Correlation of CT scanning and pathologic features of opthalmic Graves' disease. Ophthalmology $198188553-564$

47 Neigel JM, Rootman J, Belkin RI, Nugent RA, Drance SM, Beattie GW et al. Dysthyroid optic neuropathy. Ophthalmology $1988951515-1521$.
48 Nugent RA, Belkin RI, Neigel JM, Rootman J, Robertson W, Spinelli J et al. Graves' orbitopathy: correlation of CT and clinical findings. Radiology 1990177 675-682.

49 Forbes G, Gorman CA, Gehring D \& Baker HL. Computer analysis of orbital fat and muscle volumes in Graves' ophthalmopathy. American Journal of Neuroradiology 19834 737-742.

50 Forbes G, Gehring DG, Gorman CA, Brennan MD \& Jackson IT. Volume measurements of normal orbital structures by computed tomographic analysis. American Journal of Neuroradiology 19856 419-424.

51 Forbes G, Gorman CA \& Brennan MD. Ophthalmopathy of Graves' disease: computerized volume measurements of orbital fat and muscle. American Journal of Neuroradiology 19867 651-656.

52 Enzmann DR, Donaldson SS \& Kriss JP. Appearance of Graves' disease on orbital computed tomography. Journal of Computed Assisted Tomography 19793 815-819.

53 Yoshikawa K. Higashide T \& Nakase Y. Role of rectus muscle enlargement in clinical profile of dysthyroid ophthalmopathy. Japanese Journal of Ophthalmology 199135 175-181.

54 Barret L, Glatt HJ, Burde RM \& Gado MH. Optic nerve dysfunction in thyroid eye disease: CT. Radiology $1988 \mathbf{1 6 7}$ 503-508.

55 Feldon SE, Lee C, Muramatsu S \& Weiner J. Quantitative computer tomography of Graves' ophthalmopathy. Archives of Ophthalmology 1985103 213-215.

56 Hallin ES \& Feldon SE. Graves' ophthalmopathy: II. Correlation of clinical signs with measures derived from computed tomography. British Journal of Ophthalmology $1988 \mathbf{7 2}$ 678-682.

57 Hosten N, Sander B, Cordes M, Schubert CJ, Schorner W \& Felix R. Graves' ophthalmopathy: MR imaging of the orbits. Radiology 1989172 759-762.

58 Just M, Kahaly GJ, Higer HP, Rösler HP, Kutzner J, Beyer J et al. Graves' ophthalmopathy: role of MR imaging in radiation therapy. Radiology 1991179 187-190.

59 Hiromatsu Y, Kojima K, Ishisaka N, Tanaka K, Sato M, Nonaka K et al. Role of magnetic resonance imaging in thyroid-associated ophthalmopathy: its predictive value for therapeutic outcome of immunosuppressive therapy. Thyroid 19922 299-305.

60 Pauleit D, Schüller H, Textor J, Leutner C, Keller E, Sommer T et al. MR relaxation time measurements with and without selective fat suppression (SPIR) in endocrine orbitopathy. Fortschritte der Röntgenstrahlen 1997167 557-564.

61 Nianiaris N, Hurwitz JJ, Chen JC \& Wortzman G. Correlation between computed tomography and magnetic resonance imaging in Graves' orbitopathy. Canadian Journal of Ophthalmology 199429 9-12.

62 Nishikawa M, Yoshimura M, Toyoda N, Masaki H, Yonemoto T, Gondou A et al. Correlation of orbital muscle changes evaluated by magnetic resonance imaging and thyroid stimulating antibody in patients with Graves' ophthalmopathy. Acta Endocrinologica 1993129 213-219.

63 Ohnishi T, Noguchi S, Murakami N, Tajiri J, Harao M, Kawamoto $\mathrm{H}$ et al. Extraocular muscles in Graves' opthalmopathy: usefulness of T2 relaxation time measurements. Radiology $1994190857-862$.

64 Utech CI, Khatibnia U, Winter PF \& Wulle KG. MR T2 relaxation time for the assessment of retrobulbar inflammation in Graves' ophthalmopathy. Thyroid 19955 185-193.

65 Kahaly G, Diaz M, Just M, Beyer J \& Lieb N. Role of octreoscan and correlation with MR imaging in Graves' ophthalmopathy. Thyroid 19955 107-111.

66 Werner SC, Coleman DJ \& Franzen LA. Ultrasonographic evidence of a consistant orbital involvement in Graves' disease. New England Journal of Medicine 1974290 1447-1450.

67 Willinsky RA, Arenson AM, Hurwitz J \& Szalai J. Ultrasonic B scan measurement of the extraocular muscles in Graves' orbitopathy. Journal of the Canadian Association of Radiology $198435171-173$.

68 Holt JE, O'Connor PS, Douglas JP \& Byrne B. Extraocular muscle size comparison using standardized A-scan echography and 
computed tomography scan measurements. Ophthalmology 1985 92 1351-1356.

69 Delint PJ, Mourits MP, Kerlen CH, Scheenloop JJ \& WittebolPost D. B-scan ultrasonography in Graves' orbitopathy. Documenta Ophthalmologica 199385 1-4.

70 Byrne FS, Gendron E \& Glaser J. Diameter of normal extraocular muscles with echography. American Journal of Ophthalmology 1991112 706-712.

71 Given-Wilson R, Pope RM, Michell MJ, Cannon R \& McGregor AM. The use of real/time orbital ultrasound in Graves' ophthalmopathy: a comparison with computer tomography. British Journal of Radiology 198962 705-709.

72 Erickson BA, Harris GJ, Lewandowski MF, Murray KJ \& Massaro BM. Echographic monitoring of response of extraocular muscles to irradiation in Graves' ophthalmopathy. International Journal of Radiation Oncology Biology Physics 199531 651-660.

73 Prummel MF, Suttorp-Schulten MSA, Wiersinga WM, Verbeek AM, Mourits MP \& Koorneef L. A new ultrasonographic method to detect disease activity and predict response to immunosuppressive treatment in Graves' ophthalmopathy. Ophthalmology 1993100 556-561.

74 Nagy EV, Toth J, Kaldi I, Damjanovich J, Meiosi E, Lenkey A et al. Graves' ophthalmopathy: eye muscle involvement in patients with diplopia. European Journal of Endocrinology 2000142 591597.

75 Demer JL \& Kerman BM. Comparison of standardized echography with magnetic resonance imaging to measure extraocular muscle size. American Journal of Ophthalmology 1994118 351-361.

76 Benning H, Lieb W, Kahaly GJ \& Grehn F. Color Doppler ultrasound findings in patients with thyroid ophthalmopathy. Ophthalmologe 199491 20-25.

77 Krenning EP, Bakke WH, Kooij PPM, Breeman WAP, Oei HY, de Jong M et al. Somatostatin receptor scintigraphy with [111-InDTPA-D-Phe1]-octreotide in man: metabolism, dosimetry, and comparison with [123-I-Tyr-3]-octreotide. Journal of Nuclear Medicine 199233 652-658.

78 Krenning EP, Kwekkeboom DJ, Bakker WH, Breeman WAP, Kooij PPM, Oei HY et al. Somatostatin receptor scintigraphy with [111-In-DTAP-D-Phe1] and [123 I-Tyr3]-octreotide: the Rotterdam experience with more than 1000 patients. European Journal of Nuclear Medicine 199320 716-731.

79 Krenning EP, Kwekkeboom DJ, Pauwels S, Kvols LK \& Reubi JC. Somatostatin receptor scintigraphy. Nuclear Medicine Annals $19951-50$.

80 Krassas GE \& Kahaly GJ. The role of octreoscan in thyroid eye disease. European Journal of Endocrinology 1999140 373-375.

81 Wiersinga WM, Gerding MN, Prummel MF \& Krenning EP. Octreotide scintigraphy in thyroidal and orbital Graves' disease. Thyroid $1998 \mathbf{8} 433-436$.

82 Durak I, Durak H, Ergin M, Yurekli Y \& Kaynak S. Somatostatin receptors in the orbit. Clinical Nuclear Medicine $199520237-$ 242 .
83 Bohuslavizki KH, Oberwohrmann S, Brenner W. Eberhardt JU, Monig H, Clausen $\mathrm{M}$ et al. 111-In-Octreotide imaging in patients with longstanding Graves' ophthalmopathy. Nuclear Medicine Communications $199516912-916$.

84 Krassas GE, Dumas A \& Moncayo R. Octreoscan in Graves' ophthalmopathy. Thyroid $1997 \mathbf{7} 805-806$.

85 Förster GJ, Krummenauer F, Nickel O \& Kahaly GJ. Somatostatinreceptor scintigraphy in Graves' disease: reproducibility and inter-/intra-observer variability. Cancer Biotherapeutics Radiology $200021231-236$.

86 Förster GJ, Nickel O, Raab D, Andreas J \& Kahaly GJ. Somatostatin-receptor scintigraphy in Graves' ophthalmopathy. A new, standardized method for assessment of orbital disease activity. Journal of Nuclear Medicine 199940207 (Abstract).

87 Kahaly G, Diaz M, Hahn K, Beyer J \& Bockisch A. Indium-111pentetreotide scintigraphy in Graves' ophthalmopathy. Journal of Nuclear Medicine 199536 550-554.

88 Kahaly G, Görges R, Diaz M, Hommel G \& Bockisch A. Indium111-pentetreotide in Graves' disease. Journal of Nuclear Medicine $199839533-536$.

89 Kahaly GJ \& Förster GJ. Somatostatin receptor scintigraphy in thyroid eye disease. Thyroid $1998 \mathbf{8} 549-552$.

90 Postema PTE, Krenning EP, Wijngaarde R, Kooy PPM, Oei HY, van den Bosch WA et al. [111-In-DTPA-D-Phe1] octreotide scintigraphy in thyroidal and orbital Graves' disease: a parameter for disease activity? Journal of Clinical Endocrinology and Metabolism 199479 1845-1851.

91 Gerding MN, van der Zant FM, van Royen EA, Koorneef L, Krenning EP, Wiersinga WM et al. Octreotide-scintigraphy is a disease-activity parameter in Graves' ophthalmopathy. Clinical Endocrinology 199950 373-379.

92 Moncayo R, Baldnisera I, Decristoforo C, Kendler D \& Donnemiller E. Evaluation of immunological mechanisms mediating thyroid-associated ophthalmopathy by radionuclide imaging using somatostatin analog 111-In-octreotide. Thyroid $1997721-29$.

93 Krassas GE, Dumas A, Pontikides N \& Kaltsas T. Somatostatin receptor scintigraphy and octreotide treatment in patients with thyroid eye disease. Clinical Endocrinology 199542 571-580.

94 Krassas GE, Dumas A. Kaltsas T. Halkias A \& Pontikides N. Somatostatin receptor scintigraphy before and after treatment with somatostin analogues in patients with thyroid eye disease. Thyroid $1999947-52$.

95 Krassas GE, Kaltsas T, Dumas A, Pontikides N \& Tolis G. Lanreotide in the treatment of patients with thyroid eye disease. European Journal of Endocrinology 1999136 416-422.

Received 19 January 2001

Accepted 27 April 2001 